\title{
Factors Associated with Mindful Food Parenting Practices
}

\author{
Joan Giampaoli ${ }^{1}$, Keiko Goto ${ }^{1}$, Shelley R. Hart ${ }^{2}$, Sheng Yang ${ }^{3}$, and Alyson Wylie ${ }^{4}$ \\ ${ }^{1}$ Department of Nutrition and Food Science, CSU, Chico \\ ${ }^{2}$ Department of Child Development, CSU, Chico \\ ${ }^{3}$ Department of Sociology, CSU, Chico \\ ${ }^{4}$ Center for Healthy Communities (CHC), CSU, Chico
}

\begin{abstract}
Background and Purpose: The prevalence of childhood obesity remains a concern in the United States and puts children at risk for poor health. As parents are the primary caretakers of their children, the practice of mindful food parenting may help parents moderate their child's food consumption and food choices. The purpose of this research was to identify the factors associated with mindful food parenting practices among Hispanic and non-Hispanic white parents in two low-income schools in rural northern California. Methods: Two hundred ninety three parents of $3^{\text {rd }}$ through $5^{\text {th }}$ grade elementary school children completed a four part mindful food parenting practices survey developed to measure the factors associated with mindful food parenting practices. Results: Exploratory factor analysis revealed four mindful food parenting practices domains which were positively associated with several mindful food parenting practices such as eating family meals together and present-centered awareness $(p \leq 0.001)$ and cooking meals at home and hungerfullness awareness $(p \leq 0.001)$. Several demographic variables were associated with the mindful food parenting practices. Conclusions: As parents are more mindful and attentive to their child's eating behaviors, there is a greater potential for a positive parental impact on their child's food intake and types of foods consumed, and indirectly, the health of their child.
\end{abstract}

(C) 2019 Californian Journal of Health Promotion. All rights reserved.

Keywords: mindfulness, mindful food parenting practices, obesity, elementary school children

\section{Introduction}

\section{Childhood Obesity Statistics}

Child obesity remains a concern in the United States despite focused efforts on reducing this epidemic (Dalen, Brody, Staples, \& Sedillo, 2015; Skinner, Ravenbakht, Skelton, Perrin, \& Armstrong, 2018). The Centers for Disease Control and Prevention, National Center for Health Statistics (CDC-NCHS) report the prevalence of obesity among youth aged 2-19 in $2015-2016$ at $18.5 \%$ with an increase in prevalence being observed from 1999-2000 and 2015-2016. (CDC-NCHS, 2017). Hispanic youths (25.8\%) and non-Hispanic black youths (22.0\%) had higher obesity prevalence rates than non-Hispanic white youths (14.1\%) (CDC, 2018).

Children from low-income families are disproportionately affected by obesity (Singh,
Siahpush, \& Kogan, 2010). Ogden, Carroll, Fakhouri, Hales, Fryar, Li, and Freedman (2018) analyzed data from the 2011-2014 National Health and Nutrition Examination Survey (NHANES). Findings from their analysis revealed the prevalence of obesity was highest $(18.9 \%)$ in the lowest income group and lowest the highest income group (10.9\%). Further, Ogden et al., (2018) found that the prevalence of obesity decreased with the increasing level of education of the head of household.

Home environmental characteristics have been associated with obesity such as eating practices in the home, eating-related parenting styles, and family relationships (Bauer, Berge, \& NeumarkAztainer, 2011). 


\section{Home Environmental Characteristics Influence on Children's Eating Patterns}

The home environment and family lifestyle practices have an influence on children's eating patterns and food consumption (Quick, MartinBiggers, Povis, Hongu, Worobey, \& ByrdBredbenner, 2017; Trofholtz, Tate, Draxten, \& Neumark-Ztainer, 2016; Wyse, Wolfendend, \& Bisquera, 2015; Schrempft, van Jaarsveld, Fisher, \& Fildes, 2016). According to Bates, Nicholson, Cory, Jagpal and Bohnert (2018) the home environment is a central point of influence on childhood obesity. As an example, children living in households that have structure and regular routines (including family mealtimes) exhibited better overall health outcomes than children living in a chaotic environment (Fiese, Rhodes, \& Beardslee, 2013).

Quick et al., (2017) conducted a study examining the impact of family lifestyle patterns on the risk for childhood obesity. The study employed a socio-ecological perspective and included intrapersonal, interpersonal, and environmental measures. Positive intrapersonal behaviors of parents and children included consuming recommended amounts of $100 \%$ fruit/vegetable juice and a low intake and availability of soft drinks and fruit drinks. Interpersonal (family social interactions) demonstrated several positive outcomes. Participants reported that they ate meals at the table, on average, twice daily in a calm environment and without distractions. According to Burnier, Dubois, and Girard (2011) eating family meals together in a positive environment has been associated with healthier dietary intakes. Based on self-efficacy scores, parents were confident in their ability to engage in food-related practices to prevent childhood obesity and in their ability to perform these practices (Quick et al., 2017).

Research has found a positive relationship between parental intake and children's fruit and vegetable intake (Pearson, Biddle, \& Gorely, 2009; Wyse et al., 2015). In a study by Trofholz et al., (2016) the researchers found that the availability and accessibility of fruits and vegetables in the home as well as the parents' consumption of fruits and vegetables was significantly associated with these items being served at family dinners. Further, the availability and accessibility of fruits and vegetables at home has been positively associated with children's fruit and vegetable intake (Pearson, et al., 2009; Wyse et al., 2015) and decreased soft drink consumption (Verloigne, Van Lippevelde, Maes, Brug, \& Bourdeaudhuij, 2012).

Finally, parental encouragement was positively associated with children's fruit and vegetable consumption (Pearson et al., 2009). Parental permissiveness was associated with greater soft drink consumption (Verloigne et al., 2012) and lower fruit and vegetable consumption (Blissett, 2011).

With the continued prevalence of obesity among youth in the United States, there is a need to explore alternative strategies for addressing this health concern beyond traditional weight management techniques that can target obesogenic home environmental behaviors.

\section{Mindfulness and Eating}

Bays (2009) states that "Mindfulness is deliberately paying attention, being fully aware of what is happening both inside yourself-in your body, heart and mind, and outside yourself, in your environment. Mindfulness is awareness without judgment or criticism" (p.2). It is the process of recognizing the self in the present moment (Alberts, Thewissen, \& Raes, 2012). In this state of awareness, individuals are encouraged to reflect internally, increasing awareness of their physical and emotional state in the moment, without placing judgement or criticism.

Mindful eating practice is a construct of mindfulness and utilizes all of the senses in the food preparation process, from selection to consumption. It encourages individuals to be aware of the colors, textures, flavors, and other sensory characteristics of food increasing food satisfaction; and therefore, satiety (Alberts, Mulkens, Smeets, \& Thewissen, 2010; Frameson et al., 2009; Bays, 2009). Mindful eating can alter an individuals' perception of food and improve their relationship with food (O'Reilly, et al., 2014). Studies have shown that obese individuals overeat because of their desire to escape from 
reality. Therefore, mindfulness may interrupt this practice by promoting awareness about ones decision-making process regarding food choices. (Dalen et al., 2015).

Mindfulness may be a reliable strategy for treating obesity-related eating behaviors (Jordan, Wang, Donatoni, \& Meier, 2014; O’Reilly, Cook, Spruijt-Metz, \& Black, 2014). A recent metaanalysis examined 21 articles to evaluate the effectiveness of Mindfulness-Based Interventions (MBI's) on eating behaviors triggered by non-hunger related cues including emotional eating and external eating that may lead to obesity (O'Reilly et al, 2014). The researchers found that MBI's resulted in improvement in 18 (86\%) of obesity-related eating behaviors. The researchers concluded that MBI's were an effective strategy for treating obesity-related eating behaviors.

In addition, mindfulness may be associated with improved health and self-regulation, outcomes as individuals learn tools develop skills to control their portion sizes and make better food choices (Jordan et al., 2014). Using mindfulness-based strategies when eating directs individuals to appreciate the food consumed by being present in the moment and notice, without judgment, the emotions and feelings derived from eating.

\section{Parental Influence on Children's Eating Patterns}

Parents are important role models in shaping their child's dietary intake (Ventura \& Birch, 2008) and are important agents of change through which food preferences and intake patterns are established. Parents are "gatekeepers" structuring their child's eating environment, influencing their attitudes towards foods, and shaping their future eating behaviors (Hendy, 2002; Young, Ford, \& Hayes, 2004; Shloim, Edelson, Martin, \& Hetherington, 2015; Conner \& Armitage, 2002). For example, mothers who value eating meals as a family are more likely to plan dinner and ensure a scheduled dinnertime which structures the child's eating environment (McIntosh, Kubena, Tolle, Dean, Jan, \& Anding, 2010). With the societal shift to both parents working outside of the home, there may be limited time for working mothers to plan and prepare meals and they may choose convenience items instead which may be higher in salt, sugar, and fat (Rosenkranz \& Dzewaltowski, 2008) potentially shaping their child's eating behaviors. Further, eating meals in front of the television has been associated with poor diet quality and eating patterns (Marquis, Filion, \& Dagenals, 2005).

In a study by Boots et al. (2015) the researchers investigated the impact of parental feeding strategies on children's snack intake. Six hundred eleven mothers of children aged 2 through 5 years old completed an online survey examining general parenting styles and two parental feeding practices, restriction and covert control. The researchers found that higher unhealthy snack intake was associated with more restrictive parenting feeding practices and lower unhealthy snack intake was associated with covert parenting feeding practices. These findings suggest that covert parenting feeding practices, in which the parent manages the child's feeding environment as opposed to controlling it, may influence children to make healthier food choices.

\section{Mindful Parenting}

Mindful parenting has been defined as paying attention to your child and ones parenting practices intentionally, in the here and now, and non-judgmentally (Kabat-Zinn \& Kabat-Zinn, 1997). Mindful parenting helps parents to increase engagement and choose more effective parenting strategies by decreasing parental reactivity and increasing parental patience, flexibility, and responsiveness. Further, mindful parenting may enhance the parent-child relationship by improving trust and emotional sharing, decreasing parenting stress, and increasing the well-being of the child (Duncan, Coatsworth, \& Greenberg 2009).

In a study conducted by McCaffrey, Reitman, Black, \& Nierenberg (2015) the researchers developed and evaluated a tool entitled the Mindfulness in Parenting Questionnaire (MIPQ) which was used to measure mindful parenting among mothers and fathers of children ranging from 2-16 years old. Two-hundred and three parents recruited from school programs in South Florida completed the MIPQ, along with measures of intrapersonal mindfulness, parenting 
behavior, parenting style, and a demographics questionnaire. The MIPQ scores supported two mindful parenting domains: parental selfefficacy, and being in the moment with the child. Being in the moment was significantly related to parental mindfulness practice; however, parental self-efficacy did not reach significance. MIPQ scores were not related to parents' employment status or educational attainment. MIPQ scores were significantly related to parents' household income. Parents who reported a household income less than $\$ 30,000$ had lower MIPQ scores related to being in the moment than parents who made $\$ 30,000$ to $\$ 100,000$. Further, nonHispanic black parents had significantly lower scores on both MIPQ factors than non- Hispanic white and Hispanic parents. This study found no significant correlations between MIPQ scores with gender and age.

\section{Mindful Food Parenting}

Mindful food parenting examines parents' decisions regarding how they determine food choices for their child. Meers (2013) developed a Mindful Food Parenting Questionnaire (MFPQ) to measure the level of mindfulness parents exhibit when determining food choices for their child. The instrument was divided into four domains: "present-centered awareness," "present-centered emotional awareness," "nonjudgmental receptivity," and "regulate reactivity." It was theorized that mindful food parenting could be utilized to moderate the serving intakes of children as well as their food choices. As an example, an increase in parents' awareness of their children's eating behaviors may positively impact the quantity of food served, the types of food eaten, and their food parenting practices. The study found a positive relationship between healthy food practices and higher scores for mindful food parenting.

In another study examining mindful food parenting, Emley, Taylor, \& Musher-Eizenman (2017) examined the relationship between mindful feeding and parent-reported child dietary intake. Four hundred ninety-seven parents participated in the study whose children were between 2.9 to 7.5 years of age. Parents were primarily non-Hispanic white and female. The researchers found that higher parental mindful feeding was associated with higher fruit and vegetable intake and lower sugar intake among children. Further, mindful eating was associated with many indicators of a healthier diet and demonstrated promise for improving children's health outcomes.

When parents direct attention to their child's food behavior, this mindfulness influences their child's food choices as well as intake (Meers, 2013). In addition, research shows that the types of food available at home is associated with a greater consumption of these foods. Thus, healthier food available at home would lead to more consumption of those foods (Darling, Rehm, Coccia, \& Cui, 2015). Hence, how parents choose to feed their child is a determining factor of their child's future food choices, habits, and behaviors.

\section{Current Study}

The purpose of this research was to identify the factors associated with mindful food parenting practices among Hispanic and non-Hispanic white parents in two low-income schools in rural northern California. It was predicted that mindful food parenting practices will be positively associated with healthier food practices (e.g., foods available at home and involving children in meal preparation).

\section{Participants}

\section{Methods}

Participants for this cross-sectional study included Hispanic and non-Hispanic white parents of $3^{\text {rd }}$ through $5^{\text {th }}$ grade elementary school children. The parents were recruited as a convenience sample from two low-income schools in northern California. Criteria for a school to participate in the study included: 1 ) that they served a low-income, high Hispanic population district and, 2) a positive working relationship had previously been established between the researchers and the principals of the school. Five hundred surveys were distributed to parents and a total of 293 parents participated in the study for a response rate of 59\%. The study was approved by the Human Subjects Review Board at California State University, Chico (CSU, Chico) prior to implementation. 


\section{Measures}

A combination of validated measures was included in the parent survey with the goal of measuring the factors associated with mindful food parenting among Hispanic and nonHispanic white parents. The survey consisted of four main components.

Demographic Characteristics. The first section asked questions regarding participant demographics such as age, guardianship, education level, gender, race, and place of birth.

Parent Pre-post Survey (Chen et al., 2014). The second and third sections included adapted items from Chen et al., (2014). First, items were posed to inquire about the availability of specific foods (i.e., vegetables, fruits, sweets, salty snacks, soda) at home with this question "How often do you have (x) available at home?" Next, items were posed to examine the participants' food environment at home. Three different areas were addressed. Several questions were presented regarding the inclusion of items such as meal planning, grocery shopping, and food preparation (e.g. "How often do you involve your children in planning family meals?”). Several questions were presented regarding parents' encouragement of certain behaviors such a fruit and vegetable consumption, trying new foods, and mindful eating (e.g. "How many times each week do you encourage your child to eat fruits and vegetables?”). Finally, several questions were presented regarding the home food environment including eating meals together, cooking meals at home, eating meals out, eating in front of the screen, letting children choose food, and paying attention to portion sizes (e.g., "During a typical week, how many days do all, or most, of your family living in your house eat a meal together?"). The second and third sections utilized a five point Likert Rating Scale.

\footnotetext{
Mindful Food Parenting Questionnaire (MFPQ; Meers, 2013). The fourth section of the survey inquired about the participants' mindful food parenting practices utilizing the MFPQ (Meers, 2013). Statements included "I tend to feed my child while doing many other things." The MFPQ survey utilized a five-point Likert Rating Scale.
}

The parent survey was translated into Spanish and verified for accuracy by a bilingual graduate student in Nutrition and Food Science and one bilingual intern from the Center for Healthy Communities (CHC) at CSU, Chico. The survey was tested for content validity by an expert panel and pilot-tested by school staff for face validity. Changes were made accordingly based on feedback from the expert panel and pilot testing.

\section{Procedures}

The research team held meetings with the school superintendent, principals, staff, and teachers of the two schools to discuss the study and gain approval for implementation. A classroom set of parent surveys was distributed to each teacher by a researcher. Parent surveys along with a parent consent form were sent home in each student's homework folder. The surveys were to be returned within one month and parents received a \$10.00 gift card from the Grocery Outlet store as an incentive for completing the survey. To encourage completion of the parent surveys, bilingual staff members called Spanish speaking parents reminding them to complete and return the survey. The principals and teachers contacted English speaking parents and encouraged them to compete and return the survey. The Program Manager for the study visited the schools every one to two weeks during this month to encourage parents to complete the survey. Further, the Program Manager was in communication with the teachers and principals regarding ways to help increase survey return. The research team also attended Parent-Student Conferences for one week at both schools to assist parents with survey completion if they had questions. Incentives were distributed upon completion of the survey.

\section{Data Analyses}

Descriptive statistics were generated including frequencies and percentages to describe categorical variables and means and standard deviations to describe continuous or interval variables (SPSSv22). Exploratory factor analysis (EFA) was used to assess domains within the mindful food parenting questions of the MFPQ (Meers, 2013). An EFA was conducted to explore factor structure within the measure as this was noted as a limitation by Meers (2013). According to Meers (2013), further research using the 
MFPQ would be useful in fully understanding the factor structure of the measure.

EFA for one through seven factors with a Geomin (oblique) rotation with weighted least squares estimator robust to standard errors was utilized. This estimator was chosen as it does not assume normally distributed data and is better indicated for modeling categorical or ordered data (Brown, 2006). For the current study, a 15:1 (participant to variable) ratio was demonstrated, exceeding one of the most stringent recommendations of a 10:1 ratio (Costello \& Osbourne, 2005).

Several steps were followed in EFA analysis, including important decisions regarding number of factors to retain, using a) evaluation of goodness-of-fit statistics [i.e., non-significant $\chi^{2}$, SRMR $<0.08$, RMSEA $<0.06$, and CFI $>0.95$ (Hu \& Bentler, 1999), b) examination of factor structure of the model with cut-offs for "fair" $(\lambda$ $\geq 0.45$ ) to indicate acceptable factor loadings (Tabachnick \& Fidell, 2007), elimination of items that did not load significantly at that level or loaded on multiple factors, followed re-running of the EFA, and c) statistical (e.g., underidentified factors, or factors with one or no items) and theoretical (i.e., can sense be made of the factors) evaluation of the proposed factors.

Prior to the EFA analyses, data were initially screened for missingness and normality. Fifteen cases were missing data on all MFPQ variables and thus eliminated from analyses. Chi square tests did not reveal any significant differences on demographic variables for those who did not complete the MFPQ. Less than $5 \%$ of the remaining sample were missing data on any one variable. Skewness and kurtosis were investigated, with an indicator violating levels of kurtosis acceptability, and visual inspection of the data indicating some non-normality; therefore, supporting the decision to use the weighted least squares estimator. Data were screened for univariate and multivariate outliers, with four cases highlighted through $z$ scores and Mahalanobis Distance. Data were visually screened and Cook's Leverage was evaluated. The decision was made to not transform or delete these cases. Therefore, the final sample available for the EFA analysis was $n=286$. Finally, initial examination of correlations indicated several significant, low to moderate relationships among the indicator variables (i.e., $0.00 \leq r \leq 0.56$ ).

As mindful food parenting is a new concept, and this is a pilot study, only bi-variate analysis were conducted to explore and identify factors associated with mindful food parenting. Independent t-tests and ANOVA were conducted to analyze differences between the independent variables (age, gender, level of education, etc.) and the dependent variables (mindful food parenting practice domains). Spearman's Rho correlation was employed to analyze associations between the independent variables (e.g., foods available at home, child involvement in food preparation) and dependent variables (mindful food parenting practice domains). All levels of significance were set at $p<0.05$.

As a result of concerns regarding the risks for inflation of type 1 error, based on the number of tests conducted, a Bonferonni type adjustment was made (Tabachnick \& Fidell, 2007). The adjusted level of significance, therefore, was set at $p<0.001$. EFA analyses were conducted using Mplus (version 7.3; Muthen \& Muthen, 19982012) and additional data analyses were conducted using SPSS (version 22; SPSS Inc., 2013).

\section{Participants}

\section{Results}

Table 1 displays the demographic results of the participants. A total of 293 Hispanic and nonHispanic white parents participated in the survey. The majority of participants [249 (85\%)] were female and $227(77.5 \%)$ of the participants identified their race as Latino or non-Hispanic white. Approximately 117 (40\%) of participants had some college education, 79 (27\%) were high school graduates or had a GED, and 48 (16.4\%) had some high school education or less. Approximately half of the participants [154 (52.6\%)] were 35-54 years old and 127 (43.3\%) were 34 years old or younger. The majority of participants [244 (83.3\%)] were born in the United States and the predominant language spoken at home was English [230 (78.5\%)]. 
Table 1.

Demographic Data of Parents ( $N=293)$

\begin{tabular}{lrr}
\hline & & $\mathrm{n}(\%)$ \\
\hline Gender & & \\
& Female & \\
& Male & $43(14.0)$ \\
\hline Race & & \\
& Latino & $72(24.6)$ \\
& Asian & $6(2.0)$ \\
African-American & $19(6.5)$ \\
Native American & $12(4.1)$ \\
White & $155(52.9)$ \\
More than 2 races & $18(6.1)$ \\
Other & $9(3.1)$ \\
\hline Education level & \\
Some high school or less & $48(16.4)$ \\
High school grad/GED & $79(27.0)$ \\
Some college & $117(39.9)$ \\
College graduate + & $41(14.0)$ \\
\hline Age & \\
334 years & $127(43.3)$ \\
35-54 years & $154(52.6)$ \\
55 years + & $9(3.1)$ \\
\hline Place of birth & \\
United States & $244(83.3)$ \\
Mexico & $44(15.0)$ \\
\hline Language spoken at home & \\
English & $230(78.5)$ \\
Spanish & $36(12.3)$ \\
Both English \& Spanish & $14(4.8)$ \\
Other & $7(2.4)$ \\
\hline
\end{tabular}

Four Domains of Mindful Food Parenting Practices

Initial fist statistics for the EFA (see Table 2, Fit Statistics for First and Second Iteration of MFPQ EFA Models) indicated a potential of a fourthrough seven-factor model. Inspection of the factor loadings resulted in the decision to further inspect a four-factor model. Within that model, there were several items (11-12 and 14-17) that did not load at $\lambda \geq 0.45$ on any factor. Per recommendations in the literature (Tabachnick \& Fidell, 2007) these items were eliminated and the EFA was re-run. The second iteration of the EFA indicated a four- or five-factor model. The process resulted, again, in selection of a fourfactor model with two items (13 and 15) that did not load. The final iteration of the EFA indicated a four- through six-factor model. Inspection, again, resulted in a four-factor model and an interpretable solution. The final model resulted in the elimination of 7 items. As the MFPQ had been used in one study to date (Meers, 2013) it is important to continue to investigate the internal structure of a survey.

Table 2 shows the results of the final iteration of the EFA. Four factors (or domains) were identified related to mindful food parenting practices. Examination of the items from these factors resulted in the researchers identifying them as: 1$)$ present-centered awareness $(\alpha=0.69)$; 2) hunger-fullness awareness $(\alpha=0.69) ; 3)$ emotional awareness $(\alpha=0.72)$; and, 4) nonjudgmental receptivity $(\alpha=0.68)$. Factor loadings were fair to excellent $(0.50 \leq \lambda \leq 0.94)$ with no cross-loading on more than one factor $(\lambda$ $\geq 0.32$ ). Cronbach's alpha ranged from $0.68 \leq \alpha$ $\leq 0.72$ and based on suggestions in the literature, these levels, particularly in the early stages of research, are acceptable (Nunnally, 1967; Streiner, 2003). 
Table 2.

Factor Loadings Identifying Four Domains of Mindful Food Parenting Practices

\begin{tabular}{|c|c|c|c|c|}
\hline & \multicolumn{4}{|c|}{ Factor Loadings } \\
\hline & 1 & 2 & 3 & 4 \\
\hline Present-centered awareness (alpha=0.658) & & & & \\
\hline I tend to feed my child while I am doing many other things. & 0.557 & & & \\
\hline When I feed my child, I am often distracted by other thoughts. & 0.936 & & & \\
\hline $\begin{array}{l}\text { When I am feeding my child, I am completely focused on what I am } \\
\text { doing. }\end{array}$ & 0.495 & & & \\
\hline $\begin{array}{l}\text { I rush through meals with my child without really paying attention to } \\
\text { him or her. }\end{array}$ & 0.513 & & & \\
\hline Hunger-fullness awareness (alpha $=0.692)$ & & & & \\
\hline I can tell when my child is hungry. & & 0.786 & & \\
\hline I know when my child is full. & & 0.780 & & \\
\hline I encourage my child to identify and tell me when they are full. & & 0.593 & & \\
\hline Emotional awareness (alpha $=0.723)$ & & & & \\
\hline I notice how food influences my child’s behavior. & & & 0.729 & \\
\hline I am aware of how my emotions affect when and what I feed my child. & & & 0.594 & \\
\hline I notice how food affects my child's emotions. & & & 0.737 & \\
\hline Nonjudgmental receptivity (alpha $=0.683$ ) & & & & \\
\hline $\begin{array}{l}\text { When my child complains about a food I serve, I can take a step back } \\
\text { and think about this before reacting. }\end{array}$ & & & & 0.795 \\
\hline $\begin{array}{l}\text { When my child refuses to eat, I consider this calmly before doing } \\
\text { anything about it. }\end{array}$ & & & & 0.666 \\
\hline
\end{tabular}

\section{Associations between Demographics Factor Analysis Domains}

Table 3 displays the differences between the demographic variables and factor analysis domains using independent t-tests and ANOVA. Results showed that only Factor 3 (emotional awareness) resulted in statistically significant differences (using a correction for multiple comparisons) among these variables. Participants with some high school or less had significantly higher mean values for Factor $2(p<0.01)$ and Factor $3(p<0.001)$ compared with those who graduated high school or had a GED, some college, or were a college graduate.

Results also demonstrated a significant difference between race $(p<0.001)$ and language spoken at home $(p<0.001)$ mean values and Factor 3 (emotional awareness). Hispanics showed significantly higher mean values for Factor 3 as well as for those whom Spanish was their primary language spoken at home. A significant difference was displayed between place of birth mean values and Factor 2 (hungerfullness awareness) $(p<0.001)$ and Factor 3 (emotional awareness) $(p<0.001)$. Participants who were born in Mexico had significantly higher mean values for Factors 2 and 3 compared to those who were born in the U.S. Participants who ate meals at the table had significantly higher mean values for Factor 1 (present-centered awareness $)(p<0.001)$. Participants who ate meals at two or more locations had had significantly higher mean values for Factor 2 hunger-fullness awareness $(p<0.001)$. 
Table 3.

Mean, Standard Deviations, and p-Values Showing Associations between Demographic Variables and Factor Analysis Domains

\begin{tabular}{|c|c|c|c|c|c|c|c|c|}
\hline & \multicolumn{2}{|c|}{$\begin{array}{c}\text { Factor } 1 \text { Present- } \\
\text { centered awareness }\end{array}$} & \multicolumn{2}{|c|}{$\begin{array}{l}\text { Factor } 2 \text { Hunger- } \\
\text { fullness awareness }\end{array}$} & \multicolumn{2}{|c|}{$\begin{array}{c}\text { Factor } 3 \text { Emotional } \\
\text { awareness }\end{array}$} & \multicolumn{2}{|c|}{$\begin{array}{c}\text { Factor } 4 \text { Non- } \\
\text { judgmental receptivity }\end{array}$} \\
\hline & Mean (SD) & $p$ & Mean (SD) & $p$ & Mean (SD) & $p$ & Mean (SD) & $p$ \\
\hline $\begin{array}{l}\text { Guardian gender } \\
\text { a } \\
\text { Female } \\
\text { Male }\end{array}$ & $\begin{array}{l}3.60 \pm(0.76) \\
3.59 \pm(0.68)\end{array}$ & 0.97 & $\begin{array}{l}4.34 \pm(0.69) \\
4.08 \pm(0.89)\end{array}$ & 0.09 & $\begin{array}{l}3.63 \pm(0.97) \\
3.38 \pm(0.99)\end{array}$ & 0.17 & $\begin{array}{l}3.73 \pm(0.94) \\
3.43 \pm(0.81)\end{array}$ & 0.06 \\
\hline $\begin{array}{l}\text { Education level }{ }^{\mathrm{b}} \\
\text { Some HS or less } \\
\text { HS grad or GED } \\
\text { Some college } \\
\text { College grad }\end{array}$ & $\begin{array}{l}3.70 \pm(0.69) \\
3.51 \pm(0.80) \\
3.61 \pm(0.72) \\
3.60 \pm(0.72)\end{array}$ & 0.62 & $\begin{array}{l}4.66 \pm(0.53) \\
4.16 \pm(0.82) \\
4.38 \pm(0.68) \\
4.18 \pm(0.58)\end{array}$ & $0.01 *$ & $\begin{array}{l}4.18 \pm(0.92) \\
3.45 \pm(0.98) \\
3.53) \pm(1.00) \\
3.47 \pm(0.78)\end{array}$ & $0.001^{*}$ & $\begin{array}{l}3.73 \pm(0.98) \\
3.56 \pm(0.96) \\
3.76 \pm(0.92) \\
3.73 \pm(0.83)\end{array}$ & 0.49 \\
\hline $\begin{array}{l}\text { Race }^{\text {b }} \\
\text { Latino } \\
\text { White } \\
\text { Other } \\
\end{array}$ & $\begin{array}{l}3.69 \pm(0.76) \\
3.57 \pm(0.71) \\
3.57 \pm(0.80)\end{array}$ & 0.52 & $\begin{array}{l}4.40 \pm(0.85) \\
4.32 \pm(0.64) \\
4.16 \pm(0.76)\end{array}$ & 0.18 & $\begin{array}{l}3.98 \pm(0.93) \\
3.47 \pm(0.93) \\
3.51 \pm(1.04) \\
\end{array}$ & $0.001^{*}$ & $\begin{array}{l}3.68 \pm(0.99) \\
3.73 \pm(0.92) \\
3.58 \pm(0.90) \\
\end{array}$ & 0.51 \\
\hline $\begin{array}{l}\text { Place of birth }{ }^{\mathrm{b}} \\
\text { United States } \\
\text { Mexico }\end{array}$ & $\begin{array}{l}3.58 \pm(0.73) \\
3.70 \pm(0.86) \\
\end{array}$ & 0.34 & $\begin{array}{l}4.26 \pm(0.69) \\
4.57 \pm(0.75) \\
\end{array}$ & $0.01 *$ & $\begin{array}{l}3.49 \pm(0.96) \\
4.12 \pm(0.87) \\
\end{array}$ & $0.001 *$ & $\begin{array}{l}3.70 \pm(0.92) \\
3.51 \pm(0.94) \\
\end{array}$ & 0.24 \\
\hline $\begin{array}{l}\text { Age }{ }^{\mathrm{b}} \\
34 \text { yrs. or } \\
\text { younger } \\
35-54 \text { years } \\
55 \text { years or older }\end{array}$ & $\begin{array}{l}3.59 \pm(0.79) \\
3.57 \pm(0.71) \\
4.04 \pm(0.76)\end{array}$ & 0.27 & $\begin{array}{l}4.28 \pm(0.73) \\
4.32 \pm(0.72) \\
4.33 \pm(0.92)\end{array}$ & 0.91 & $\begin{array}{l}3.56 \pm(1.05) \\
3.62 \pm(0.92) \\
3.56 \pm(0.83)\end{array}$ & 0.88 & $\begin{array}{l}3.50 \pm(0.98) \\
3.80 \pm(0.86) \\
3.86 \pm(0.80)\end{array}$ & $0.03 *$ \\
\hline $\begin{array}{l}\text { Language }{ }^{\mathrm{b}} \\
\text { English } \\
\text { Spanish } \\
\text { Both languages } \\
\text { Other }\end{array}$ & $\begin{array}{l}3.58 \pm(0.72) \\
3.62 \pm(0.81) \\
3.91 \pm(0.62) \\
3.50 \pm(1.41)\end{array}$ & 0.45 & $\begin{array}{l}4.26 \pm(0.70) \\
4.56 \pm(0.73) \\
4.48 \pm(0.88) \\
4.56 \pm(0.78)\end{array}$ & 0.12 & $\begin{array}{l}3.47 \pm(0.97) \\
4.22 \pm(0.91) \\
4.00 \pm(0.87) \\
4.00 \pm(0.67)\end{array}$ & $0.001 *$ & $\begin{array}{l}3.70 \pm(0.92) \\
3.63 \pm(1.05) \\
3.82 \pm(0.70) \\
3.08 \pm(1.16)\end{array}$ & 0.34 \\
\hline $\begin{array}{l}\text { Meal location } \\
\text { At the table } \\
\text { On the couch } \\
\text { Separate rooms } \\
2 \text { or more choices } \\
\text { Other } \\
\text { Total }\end{array}$ & $\begin{array}{l}3.74 \pm(0.70) \\
3.07 \pm(0.53) \\
3.21 \pm(1.16) \\
3.39 \pm(0.71) \\
2.96 \pm(0.97) \\
3.61 \pm(0.74)\end{array}$ & $0.001^{*}$ & $\begin{array}{l}4.36 \pm(0.71) \\
3.88 \pm(0.81) \\
3.83 \pm(0.69) \\
4.40 \pm(0.61) \\
3.38 \pm(0.69) \\
4.29 \pm(0.73)\end{array}$ & $0.001 *$ & $\begin{array}{l}3.65 \pm(0.97) \\
3.18 \pm(1.07) \\
3.39 \pm(0.53) \\
3.40 \pm(1.03) \\
3.52 \pm(0.90) \\
3.57 \pm(0.98)\end{array}$ & 0.25 & $\begin{array}{l}3.74 \pm(0.91) \\
3.15 \pm(1.11) \\
3.92 \pm(0.58) \\
3.69 \pm(1.02) \\
3.21 \pm(0.57) \\
3.68 \pm(0.94)\end{array}$ & 0.053 \\
\hline
\end{tabular}

Note: SD = Standard deviation

${ }^{a}$ Independent $t$-test was used to determine differences in mean gender scores and factor analysis domains

${ }^{b}$ ANOVA was used to determine differences in education level, race, place of birth, age, language and meal location mean scores and factor analysis domains

Mindful Eating Parenting Questionnaire Factors 1-4: average scores out of 5.0; higher scores indicate greater frequency of awareness of behaviors (1=never true; $2=$ =rarely true; $3=$ often true; $4=$ =usually true; $5=$ always true

$\mathrm{N}$ varies depending on response rate

*Indicates statistical significance at the $\mathrm{p}<0.001$ based on the Bonferroni adjustment

\section{Associations between Food Availability at Home, Child's Participation in Shopping, and Meal Planning/Preparation and Factor Analysis Domains}

A Spearman's Rho correlation test was utilized to analyze associations between the independent variables such as food available at home, children's participation in shopping and meal planning/preparation and the four factor analysis domains. Table 5 shows these associations and levels of significance.

\section{Factor 1 (Present-centered Awareness)}

Spearman's Rho correlations displayed inverse associations between Factor 1 and the availability of sweets and salty snacks $(p<0.001)$, and soda at home and number of meals eaten out $(p<0.001)$. Encouraging fruit and vegetable consumption 
$(p<0.001)$, eating family meals together $(\mathrm{p}<0.001)$, cooking meals at home $(p<0.001)$ and paying attention to portion sizes $(p<0.001)$ were positively associated with Factor 1.

Factor 2 (Hunger-fullness Awareness)

Variables positively associated with Factor 2 included parents involving children in meal planning $(p<0.001)$, family eating meals together $(p<0.001)$, cooking meals at home $(p<0.001)$, paying attention to child's portion sizes $(p<0.001)$ and encouraging mindful eating at home $(p<0.001)$.

\section{Factor 3 (Emotional Awareness)}

Correlational analysis displayed positive associations between Factor 3 and parents involving children in meal planning $(p<0.001)$ and food preparation $(p<0.001)$ and parents encouraging mindful eating $(p<0.001)$.

\section{Factor 4 (Non-judgmental Receptivity)}

Variables positively associated with Factor 4 included eating family meals together $(p<0.001)$ and parents paying attention to their child's portion sizes $(p<0.001)$.

Table 4.

Spearman's Rho Correlation between Demographic Characteristics and Factor Analysis Domains

\begin{tabular}{lrrrr}
\hline & $\begin{array}{r}\text { Present-centered } \\
\text { awareness }\end{array}$ & $\begin{array}{r}\text { Hunger-fullness } \\
\text { awareness }\end{array}$ & $\begin{array}{r}\text { Factor 3 } \\
\text { Emotional } \\
\text { awareness }\end{array}$ & $\begin{array}{r}\text { Non-judgmental } \\
\text { receptivity }\end{array}$ \\
\cline { 2 - 5 } & $\mathrm{r}(p)$ & $\mathrm{r}(p)$ & $\mathrm{r}(p)$ & $\mathrm{r}(p)$ \\
\hline Number of children & $-0.07(0.290)$ & $0.07(0.252)$ & $-0.02(0.816)$ & $-0.11(0.078)$ \\
Vegetable availability & $0.12(0.057)$ & $0.094(0.128)$ & $-0.01(0.837)$ & $0.07(0.259)$ \\
Fruit availability & $0.13\left(0.036^{*}\right)$ & $0.13\left(0.042^{*}\right)$ & $0.12(0.057)$ & $0.10(0.106)$ \\
Sweet availability & $-0.20\left(0.001^{* *}\right)$ & $-0.09(0.128)$ & $-0.07(0.238)$ & $0.08(0.10)$ \\
Salty snack availability & $-0.20\left(0.001^{* *}\right)$ & $-0.06(0.335)$ & $-0.10(0.103)$ & $-0.01(0.908)$ \\
Soda availability & $-0.15(0.013)$ & $-0.06(0.339)$ & $-0.06(0.361)$ & $-0.07(0.279)$ \\
Involve children in meal planning & $0.10(0.110)$ & $0.20\left(0.001^{* *}\right)$ & $0.28\left(0.001^{* *}\right)$ & $0.17\left(0.005^{*}\right)$ \\
Involve children in grocery & $-0.03(0.689)$ & $0.14\left(0.031^{*}\right)$ & $0.18\left(0.004^{* *}\right)$ & $0.05(0.382)$ \\
shopping & & & & \\
Involve children in food & $0.03(0.605)$ & $0.18\left(0.003^{* *}\right)$ & $0.21\left(0.001^{* *}\right)$ & $0.13\left(0.038^{*}\right)$ \\
preparation & & & & \\
Encourage fruit and vegetable & $0.21\left(0.001^{* *}\right)$ & $0.13\left(0.037^{* *}\right)$ & $-0.01(0.993)$ & $0.10(0.108)$ \\
consumption & & & & \\
Encourage new food & $-0.04(0.530)$ & $0.10(0.122)$ & $0.16\left(0.012^{*}\right)$ & $0.04(0.547)$ \\
Encourage mindful eating & $0.18(0.060)$ & $0.26\left(0.001^{* *}\right)$ & $0.27\left(0.001^{* *}\right)$ & $0.13\left(0.035^{*}\right)$ \\
Family eats meals together & $0.36\left(0.001^{* *}\right)$ & $0.22\left(0.001^{* *}\right)$ & $0.17^{* *}\left(0.007^{* *}\right)$ & $0.23\left(0.001^{* *}\right)$ \\
Cooking meals at home & $0.31\left(0.001^{* *}\right)$ & $0.24\left(0.001^{* *}\right)$ & $0.18^{* *}\left(0.004^{*}\right)$ & $0.19\left(0.002^{*}\right)$ \\
Meals eaten out & $-0.21\left(0.001^{* *}\right)$ & $-0.13^{*}\left(0.035^{*}\right)$ & $-0.03(0.672)$ & $-0.033(0.595)$ \\
Let children eat in front of screen & $-0.18\left(0.004^{*}\right)$ & $-0.06(0.323)$ & $-0.02(0.765)$ & $-0.01(0.906)$ \\
Let children choose food & $-0.11(0.073)$ & $-0.01(0.826)$ & $0.04(0.523)$ & $0.02(0.793)$ \\
Pay attention to portion sizes & $0.28\left(0.001^{* *}\right)$ & $0.27^{* *}\left(0.001^{* *}\right)$ & $0.08(0.211)$ & $0.20^{* *}\left(0.001^{* *}\right)$ \\
\hline
\end{tabular}

\section{Discussion}

\section{Exploratory Factor Analysis and the MFPQ Structure}

The purpose of this research was to identify factors that were associated with mindful food parenting practices among Hispanic and nonHispanic white parents in two low-income schools. Findings from this research revealed modified MFPQ domains from those originally identified by Meers (2013). Exploratory factor analysis (EFA) did not demonstrate a good fit using the original 19-item questionnaire. However, we were able to obtain a moderate to adequate fit by removing 7 items, four from the regulate reactivity domain and three from the nonjudgmental receptivity domain. Using EFA, three of the domains remained consistent with Meers (2013) findings: 1) present-centered awareness; 2) emotional awareness; and 3) 
nonjudgmental receptivity. The domain related to present-centered awareness measured how fully present in the moment parents are when feeding their child and included questions such as "When I am feeding my child, I am fully focused on what I am doing.” The emotional awareness domain measured parents' ability to understand/recognize their child's feelings related to food and included questions such as "I notice how food influences my child's behavior." The domain related to nonjudgmental receptivity measured parents' ability to be open and nonjudgmental regarding their own reaction to their child's response to food. Questions for this domain included "When my child complains about a food I serve, I can take a step back and think about this before reacting” as an example. Results from this research suggested a fourth domain, hunger-fullness awareness, in contrast to regulate reactivity, which included questions such as "I can tell when my child is hungry."

\section{Demographic Variables Associated with the MFPQ Domains}

Results from this study revealed several demographic variables associated with the mindful food parenting practice domains including race, education level, age, and meal location.

Factor 1 (Present-centered Awareness). Parents who ate meals at the table with their child had stronger associations for present-centered awareness. Meers (2013) suggested that when parents are mindful of their child's food behaviors, this awareness may influence their child's food choices as well as intake. Duncan, Coatsworth, and Greenberg (2009) suggested that mindful parenting helps parents to increase parent-child engagement and be in the moment. These findings are similar to those found by McCaffrey, et al., (2015) in which they found that being in the moment was significantly related to parental mindfulness practice.

Factors 2 and 3 (Emotional Awareness and Hunger-fullness Awareness). Hispanic parents showed a stronger association with emotional awareness and hunger-fullness awareness compared to non-Hispanic white parents. Food traditions and the preparation of traditional foods may be more integrally connected to these factors among Hispanic parents than in the non-Hispanic white parents. Parents with some high school or less were more positively associated with emotional awareness and hunger-fullness awareness than parents with more advanced education. Parents with higher education may be more career focused; and therefore, encounter a greater amount of distractions limiting their ability to be fully engaged in mindful food parenting practices.

Factor 4 (Non-judgmental Receptivity). Age was associated with nonjudgmental receptivity among 35-54 year olds. This result could potentially be due to generational differences. This generation is more diverse than previous generations and; therefore, may be more accepting and non-judgmental of persons and behaviors different from their own.

Some surprising findings also emerged. Gender was not associated with mindful food parenting practices even though women are generally the primary caretakers of their children. Both parents may be taking more of an active role in child rearing with the need for both parents to work to remain financially viable. Further, parents who ate meals in two or more locations demonstrated a stronger association with hunger-fullness awareness. Parents may choose locations to eat meals that are calm and non-distracting whether it be at the table, on the couch, or in a separate room, allowing them to remain focused on their hunger and fullness levels.

\section{Mindful Food Parenting Practices and the MFPQ Domains}

Findings from the research revealed several strong positive associations between mindful food parenting practices and the four factor analysis domains. Eating family meals together and cooking meals at home were strongly correlated with all of the factor analysis domains.

Factor 1 (Present-centered Awareness). Factor 1 was strongly correlated with parent's encouraging fruit and vegetable consumption and paying attention to portion sizes. In contrast, Factor 1 had a strong inverse correlation with parents having sweet and salty snacks available at 
home, eating more meals out, and letting their child eat in front of a screen. These finding are consistent with the study conducted by Emley et al., (2017) in which the researchers found that higher mindful food parenting was associated with higher fruit and vegetable intake and lower sugar intake among children. Further, research by McCaffrey, et al., (2015) found that being in the moment was significantly related to parental mindfulness practice.

Factor 2 (Hunger-fullness Awareness). Factor 2 was strongly correlated with parents involving children in meal planning and food preparation, encouraging mindful eating, and paying attention to portion sizes. Jordon et al., (2014) found that mindfulness may be associated with improved self-regulation as individuals' develop skills to control their portion sizes and make better food choices. Meers (2013) theorized that mindful food parenting could be utilized to moderate the serving intakes of children as well as their food choices. An increase in parents' awareness of their child's eating behaviors may positively impact the quantity of food served and the types of food eaten.

Factor 3 (Emotional Awareness). Factor 3 was strongly associated with parents involving children in meal planning, grocery shopping, and food preparation, as well as encouraging mindful eating. O'Reilly et al., (2014) found that eating behaviors triggered by non-hunger related cues, including emotional eating and external eating, may lead to obesity. The researchers found that Mindfulness -Based Interventions (MBI’s) resulted in improvement of obesity-related eating behaviors and concluded that MBI's were an effective strategy for treating obesity-related eating behaviors.

Factor 4 (Non-judgmental Receptivity). Factor 4 was strongly correlated with parents involving children in meal planning and paying attention to portion sizes. Boots et al. (2015) found that higher unhealthy snack intake was associated with more restrictive parenting feeding practices and lower unhealthy snack intake was associated with a more open and non-judgmental parenting feeding practices. According to Duncan and Coastworth (2009) mindful parenting increases engagement and helps parents choose more effective parenting strategies by decreasing parental reactivity and increasing parental patience, flexibility, and responsiveness.

\section{Limitations}

There were several limitations to this pilot study. Three of the four factor analysis domains for mindful food parenting practices showed moderate to adequate internal consistency indicating individual items may not have loaded in the appropriate domain. Further, this study was conducted in two schools in rural northern California and may not be representative of other regions of the country. The study relied on selfreport data from parents. Actual mindful food parenting practices at home was not measured nor BMI's of the families. In addition, this research utilized a cross-sectional study design; therefore, cause-and-effect relationships cannot be determined. Finally, since mindful food parenting is a new concept and this is a pilot study, only bivariate analyses were conducted to identify factors associate with mindful food parenting. Future research with a bigger sample size is needed to conduct multivariate analyses and better understand the factors associated with mindful food parenting including possible interactions between factors as well as demographic variables.

\section{Conclusions}

In conclusion, the researchers of this current study predicted that mindful food parenting practices would be positively associated with healthier food practices such as types of foods available at home and parents involving children in meal planning. The findings from this study demonstrate this association and further contribute to the literature. Several factors that contribute to mindful food parenting practices were revealed from this study that are consistent with the current literature (e.g., families eating meals at the table, parents encouraging fruit and vegetable consumption, and parents involving children in paying attention to their hungerfullness cues).

Mindful food parenting emphasizes moderating the parent's response to their child's eating behaviors as well as the child's food consumption 
and choice (Musher-Eizenman \& Keifner, 2013). Meers (2013) states that mindful food parenting may assist parents in learning alternate strategies to poor eating habits while developing healthier food parenting habits. As an example, parents can learn techniques to become aware of any reactivity that occurs in response to meal times and their child's requests for food and engage in mindfulness practices during feeding activities. These techniques can be targeted to parents' automatic reactions (Duncan, et al., 2009). In changing parents' automatic and undesirable food habits, increased mindful parenting practices can help parents change their child's unhealthy eating behaviors, promote healthful eating behaviors, and overall health.

Although obesity status was not measured (e.g. BMI), mindful food parenting practices may be a viable strategy for treating obesity and improving children's health outcomes. Based on these findings, the current study suggests that parents who are more mindful in their feeding tend to feed their children in a variety of healthy ways. As parents are more aware of and attentive to their child's eating behaviors, there is a greater potential for a positive parental impact on their child's food intake and types of foods consumed, and indirectly, the health status of their child. Thus, encouraging mindfulness in the food parenting context may be a key aspect of helping parents feed their children in a manner that reflects their healthy feeding goals.

\section{Role of Funding Sources}

Research relating to this article was funded with a grant from the United States Department of Agriculture - Agricultural Food and Research Initiative (AFRI program) (Grant/Award \#: 2015-69001-23238). The funding sources had no role in the study design, collection, analysis or interpretation of the data, writing the manuscript, or the decision to submit the paper for publication.

\section{References}

Alberts, H. J. E. M., Mulkens, S., Smeets, M., \& Thewissen, R. (2010). Coping with food cravings. Investigating the potential of a mindfulness-based intervention. Appetite, 55, 160-163.

Alberts, H. J. E. M., Thewissen, R., \& Raes, L. (2011). Dealing with problematic eating behavior. The effects of a mindfulness-based intervention on eating behavior, food cravings, dichotomous thinking and body image concern. Appetite, 58, 847-851.

Bates, C. R., Buscerni, J., Nicholson, L. M., Cory, M., Jagpal, A., \& Bohnert, A. M. (2018). Links between the organization of the family home and environment and child obesity: A systematic Review. Obesity Reviews, 19, 716-727.

Bauer, K.W., Berge, J.M., \& Neumark-Sztainer, D. (2011). The importance of families to adolescents' physical activity and dietary intake. Adolescent Medical State of the Art Review, 22, 601-613.

Bays, J. C. (2009). Mindful eating. A guide to rediscovering a healthy and joyful relationship with food. Boston, MA: Shambhala Publications, Inc.

Blissett, J. (2011). Relationhips between parenting style, feeding style, and feeding practices and fruit and vegetable consumption in early childhood. Appetite, 57(3), 826-831.

Boots, S. B., Tiggemann, M., Corsini, N., \& Mattiske, J. (2015). Managing young children's snack food intake. The role of parenting style and feeding strategies. Appetite, 92, 94-101.

Burnier, D., Dubois, L., \& Girard, M. Arguments at mealtime and child energy intake. (2011). Journal of Nutrition Education and Behavior, 43, 473-481. doi: 10.1016/j.jneb.2011.01.005.

Centers for Disease Control and Prevention. (2018). Prevalence of childhood obesity in the United States, Retrieved from: https://www.cdc.gov/obesity/data/childhood.html.

Centers for Disease Control and Prevention, National Center for Health Statistics. (2017). Prevalence of obesity among adults and youth: United States, 2015-2016 (National Center for Health Statistics Data Brief No. 288, October 2017). Retrieved from: https://www.cdc.gov/nchs/products/databriefs/db288.htm.

Chen, Q., Goto, K., Wolff, C., Bianco-Simeral, S., Gruneisen, K., \& Gray, K. (2014). Cooking up diversity. Impact of a multicomponent, multicultural, experiential intervention on food and 
cooking behaviors among elementary-school students from low-income ethnically diverse families. Appetite, 80, 114-122. DOI: 10.1016/j.appet.2014.05.009/.

Conner, M. \& Armitage. C.J. (2002). The Social Psychology of Food. Buckingham: Open University Press.

Costello, A., \& Osbourne, J. (2005). Best practices in exploratory factor analysis: Four recommendations for getting the most from your analysis. Practical Assessment Research\& Evaluation, 10(7), 1-9.

Dalen, J., Brody, J. L., Staples, J. K., \& Sedillo, D. (2015). A conceptual framework for the expansion of behavioral interventions for youth obesity: A family-based mindful eating approach. Childhood Obesity, 11(5), 577-584.

Darling, C. A., Rehm, M., Coccia, C., \& Cui, M. (2015). Adolescent eating behavior: The role of indulgent parenting. Families in Society, 96(4), 257-267.

Duncan, L. G., Coatsworth, D. J., \& Greenber, M. T. (2009). A model of mindful parenting: Implications for parent-child relationships and prevention research. Clinical Child and Family Psychology Review, 12, 255-270.

Emley, E.A., Taylor, M.B., \& Musher-Eizenman, D.R. (2017). Mindful feeding and child dietary health. Eating Behaviors, (24), 89-94. http://doi.org/10.1016/j.eatbeh.2016.12.002.

Fiese, B. H., Rhodes, H. G., \& Braedslee, W. R. (2013). Rapid changes in American family life: Consequences for child health and pediatric practice. Journal of Pediatrics, 3, 552-559.

Frameson, C., Kristal, A. R., Schenk, J., Littman, J., Zeliadt, S., \& Benitez, D. (2009). Journal of the American Dietetic Association, 109(8), 1439-1444.

Hendy, H. M. (2002). Effectiveness of trained peer models to encourage food acceptance in preschool children. Appetite, 39(3), 217-225.

Hu, L. \& Bentler, P. (1999). Cutoff criteria for fit indices in covariance structure analysis: conventional criteria versus new alternatives. Structural Equation Modeling, 6, 1-55.

Jordan, C. H., Wang, W., Donatoni, L., \& Meier, B. P. (2014). Mindful eating: Trait and state mindfulness predict healthier eating behavior. Personal and Individual Differences, 68, 107-111.

Kabat-Zinn, M. \& Kabat-Zinn, J. (1997). Everyday blessings: The inner work of mindful parenting. New York, NY: Hyperion Books.

Marquis, M., Filion, Y.P., \& Dagenals, F. (2005). Does eating while watching television influence children's food-related behaviours? Canadian Journal of Dietetic Practice and Research, 66(1), 12-18.

McCaffrey, S., Reitman, D., Black, R., \& Nierenberg, B. (2015). Mindfulness in parenting questionnaire (MIPQ): Development and validation of a measure of mindful parenting (Doctoral dissertation, Nova Southeastern University). Retrieved from: file://D:/CSU,\%20Chico/Manuscripts/Manuscripts/CJHP\%20Article\%20\%20Mindful 20Eating\%20and\%20Food\%20Parenting\%20Practices/Mindfulness\%20I\%20Parenting 20Questionnaire\%20(MIPQ)_\%20Development\%20and\%20va.pdf.

McIntosh, W.A., Kubena, K.S., Tolle, G., Dean, W.R., Jan, J.S., \& Anding, J. (2010). Mothers and meals. The effects of mothers meal planning and shopping motivation on children's participation in family meals. Appetite, 55(3), 623-628.

Meers, M. R. (2013). The assessment of mindful food parenting and its relation to parental feeding practices and child food intake. (Doctoral Dissertation, Bowling Green State University, Bowling Green, Ohio). Retrieved from https://etd.ohiolink.edu/.

Musher-Eizenman, D. R., \& Kiefner, A. (2013). Food parenting: A selective review of current measurement and an empirical examination to inform future measurement. Childhood Obesity, 9(1), 32-39.

Muthen, L.K. \& Muthen, B.O. (1998-2012). Mplus user's guide. Los Angeles, CA: Muthen \& Muthen. Nunnally, J.C. (1967). Psychometric theory. New York, NY: McGraw Hill.

Ogden, C.L., Carroll, M.D., Fakhouri, T.H., Hales, C.M., Fryar, C.D. Li, X., \& Freedman, D.S. (2018). Prevalence of obesity among youths by household income and education level of head of 
household - United States 2011-2014. Morbidity and mortality weekly report (MMWR). Retrieved from: https://www.cdc.gov/mmwr/volumes/67/wr/mm6706a3.htm?s_cid=mm6706a3_w

O'Reilly, G. A., Cook, L., Spruijt-Metz, D., \& Black, D. S. (2014). Mindfulness-based interventions for obesity-related eating behaviors: A literature review. Obesity Review, 15, 453-461.

Quick, V., Martin-Biggers, J., Povis, G.A., Hongu, N., Worobey, J., \& Byrd-Bredbenner, C. (2017). A socio-ecological examination of weight-related characteristics of the home environment and lifestyles of households with children. Nutrients, 9, 604. doi:10.3390/nu9060604.

Pearson, N., Biddle, S. J., \& Gorely, T. (2009). Family correlates of fruit and vegetable consumption in children and adolescents: A systematic review. Public Health Nutrition, 12(2), 267-283.

Rosenkranz, R.R., \& Dzewaltowski, D.A. (2008). Model of the home food environment pertaining to childhood obesity. Food and Nutrition Bulletin, 32(2), 75-83.

Schrempft, S., van Jaarsveld, C.H.M., Fisher, A., \& Fildes, A. (2016). Maternal characteristics associated with the obesogenic quality of the home environment in early childhood. Appetite, 107, 392-397.

Shloim, N., Edelson, L. R., Martin, N., \& Hetherington, M. M. (2015). Parenting styles, feeding styles, feeding practices, and weight status in 4-12 year-old children: A systematic review of the literature. Frontiers in Psychology, 6, 1-20.

Singh, G.K., Siapush, M., \& Kogan, M.D. (2010). Rising social inequalities in U.S. childhood obesity. Annuls of Epidemiology, 201(1), 40-52.

Skinner, A.C., Ravanbakht, S.N., Skelton, J.A., Perrin, E.M., \& Armstrong, S.C. (2018). Prevalence of obesity and severe obesity in U.S. children, 1999-2016. Pediatrics, 141(3), https://doi.org/10.1542/peds.2017-3459.

Streiner, D.L. (2003). Starting at the beginning: An introduction to coefficient alpha and internal consistency. Journal of Personality Assessment, 80(1), 99-103.

Tabachnick, B.G., \& Fidell, L.S. (2007). Using multivariate statistics. Boston, MA: Allyn \& Bacon/Pearson Education.

Trofholz, A.C., Tate, A.D., Draxten, M.L., \& Neumark-Sztainer, D. (2016). Home food environment factors associated with the presence of fruit and vegetables at dinner: A direct observational study. Appetite, 96, 526-532.

Ventura, A.K., \& Birch, L.L. (2008). Does parenting affect children's eating and weight status? International Journal of Behavioral Nutrition and Physical Activity, 5:15.

Verloigne, M., Van Lippevelde, W., Maes, L., Brug, J., \& De Bourdeaudhuij, I. (2012). Family- and school-based correlates of energy-balanced related behaviors in 10-12 year-old children: A systematic review within the ENERGY (EuropeaN Energy balance Research to prevent excessive weight Gain among Youth) project. Public Health Nutrition, 15(8), 1380-1395.

Wyse, R., Wolfenden, L., \& Bisquera, A. (2015). Characteristics of the home environment that mediate immediate and sustained increases in child fruit and vegetable consumption: mediation analysis from the Healthy Habits cluster randomized controlled trial. International Journal of Behavioral Nutrition and Physical Activity, 12, 118. doi: 10.1186/s12966-015-0281-6.

Young, E.M., Fors, E.W., \& Hayes, D.M. (2004). Associations between perceived parent behaviors and middle school fruit and vegetable consumption. Journal of Nutrition Education and Behavior, 36(1), 2-8. 


\author{
Author Information \\ Joan Giampaoli, PhD, RDN, Associate Professor and DI \\ Director \\ Department of Nutrition and Food Science, CSU, Chico \\ $400 \mathrm{~W} .1^{\text {st }}$ St., Chico, CA, 95929-0002 \\ jgiampaoli@csuchico.edu \\ (530-898-6410)
}

